\title{
Social representations of Britishness among British South Asian gay men
}

\author{
Rusi Jaspal \& Razina Ferozali \\ Nottingham Trent University, UK
}

\begin{abstract}
Nationhood can be conceptualised in many different ways and these conceptualisations determine the level of access that ethnic minorities have to a national identity. This study focuses on social representations of Britishness among British South Asian gay men and their impact for constructing and managing national, ethnic and sexual identities. Fifteen individuals were interviewed using a semi-structured interview schedule and the data were analysed using thematic analysis and social representations theory. The analysis yielded three themes focusing on the racial representation of Britishness, which emphasised the centrality of race and was perceived to be exclusionary; the multicultural representation, which facilitated both ethnic and British national identification but did not address homophobia in the ethnic ingroup; and the civic/ instrumental representation, which facilitated a sense of belonging in spite of their multiple identities. A civic/ instrumental representation of Britishness appears to be inclusive and may have far-reaching social and psychological benefits.
\end{abstract}

\section{Keywords}

Britishness, national identity, British South Asians, gay men, social representations theory

\section{Introduction}

National identity can be defined in terms of the individual's attitude towards the nation, the extent to which they identify as a member of this group and the level of importance that they append to this group membership. A strong national identity is beneficial for psychological wellbeing as it provides a sense of belonging, self-esteem and positive distinctiveness from others (Cinnirella, 1997; Jaspal \& Cinnirella, 2013). Yet, it is generally recognised that access to, and identification with, Britishness varies across the diverse communities in the United Kingdom. There are multiple social and psychological factors that can impinge on national identification among individuals of ethnic minority background. These can include state acculturation ideology, perceived acceptance and inclusion from fellow co-nationals, racism and others (Robinson, 2009).

As the largest visible ethnic minority in the United Kingdom, the South Asian diaspora has been the focus of research and commentary concerning national identity (Dwyer, 2000; Maxwell, 2006, 2009; Modood, 2005), with some important contributions from social psychology (Cinnirella \& Hamilton, 2007; Jacobson, 1997; Jaspal, 2015; Vadher \& Barrett, 2009). However, there is as yet no social psychological research into national identity among British South Asians with non-heterosexual identities. It is important to understand how national identity is conceptualised and how it operates within the self-concept in relation to other identities, such as ethnicity and sexuality, within this under-explored population. Accordingly, this exploratory study examines social representations of Britishness among British South Asian gay men (BSAGM) and their impact for constructing and managing national, ethnic and sexual identities.

\section{National identity among British South Asians}

Significant societal events, such as the 9/11 attacks in New York in 2001 and the July $7^{\text {th }} 2005$ bombings in London clearly affected intergroup relations and raised questions about sense of national belonging in ethnic minorities groups - especially among those who self-identify as Muslim (Cinnirella, 2014; Jaspal \& Cinnirella, 2010). Yet, even before these events, there had 
been debates about Britishness in South Asian minority communities (Ballard, 1994; Ghuman, 2003).

There have been several largely sociological studies of British national identity in this population which have yielded mixed findings. Hussain and Bagguley (2005) found that their British Pakistani participants laid claim to a British national identity due to their citizenship rights (see also Manning \& Roy, 2010). Similarly, in his analysis of Home Office survey data, Maxwell (2009) found that South Asians were more likely to self-identify as British than Black Caribbean respondents. Yet, there is also evidence that some British South Asians experience challenges in reconciling their national and ethnic identities (Sekhon \& Szmigin, 2011), especially due to perceived discrimination from the White British majority (Maxwell, 2006; Robinson, 2009). Moreover, in some research, length of residence in the United Kingdom is positively correlated with British national identification (Burholt, Dobbs \& Victor, 2016).

The variable findings may be attributed to the fluctuating meanings of Britishness among respondents and the ways in which they have been captured in empirical research. Furthermore, it should also be acknowledged that Britishness may be understood in different ways in different parts of the United Kingdom - in Scotland, for instance, some resist a British national identity, which may be viewed as a competitor with their Scottishness (Kiely, McCrone \& Bechhofer, 2005). Furthermore, recent debates about 'Brexit' (the United Kingdom's departure from the European Union) have reinvigorated discussions about Britishness - in the devolved nations, in particular.

According to social identity theory (Tajfel \& Turner, 1986), national identity can be thought of in terms of a social group membership which acquires salience in some contexts and provides feelings of distinctiveness and self-esteem when it does (Spinner-Halev \& TheissMorse, 2003). Kelman (1997) differentiates between two types of national identity: sentimental attachment, which refers to an emotional attachment to the nation perceived to correspond to one's personal identity; and instrumental attachment whereby the nation is perceived to serve practical needs of the individual and, thus, the institutional dimension is of psychological primacy. Sociological research into national identity has distinguished between ethnic and civic conceptions of nationhood, providing a dichotomous explanation for how ethnic minorities can access a British national identity (Smith, 1991, 1998).

In a similar vein, there has been valuable research into the 'boundaries of Britishness' among British South Asian young adults, which incorporate these theoretical tenets. It essentially posits that there is no monolithic understanding of British national identity in this population but rather a series of diverse context-specific notions of Britishness. In an early study, Jacobson (1997) found that British Pakistani Muslim interviewees defined Britishness in three different ways - in terms of whiteness and having British ancestry (racial boundary); as a political category to which one has access if one has British citizenship (civic boundary); and as accessible to those whose norms, values and lifestyle are 'typically British' (cultural boundary).

In their subsequent research into British Pakistani and British Indian young adults, Vadher and Barrett (2009) described additional boundaries, including the multicultural and instrumental boundaries, which refer to the notions that Britishness is characterised by cultural heterogeneity and that it serves particular practical needs of the individual (e.g. providing access to education and healthcare), respectively. The authors highlight the inclusivity of the multicultural boundary and, thus, make a case for its promotion at a policy level. This work is important because it captures the variability of Britishness and enables us to examine how individuals identify with this category. However, it is unclear how the boundaries of Britishness operate among BSAGM who potentially face several layers of exclusion, including from their ethnic ingroup. Moreover, it is unclear how particular representations of Britishness 
shape self-identification with the nation and indeed other social categories (e.g. sexuality, ethnicity).

\section{British South Asian gay men}

There has been some work on the identities and experiences of BSAGM, which generally highlights the social and psychological challenges associated with their complex self-concept - consisting of ethnic, religious and sexual identities (Jaspal \& Cinnirella, 2010, 2012; Jaspal, Lopes \& Rehman, 2019; Jaspal \& Siraj, 2011; Yip, 2004). There is evidence that attitudes towards sexual diversity in British Asian communities tend to be negative and that social stigma is pervasively appended to sexual minorities (BBC, 2018; Jaspal, 2020). Although there is some debate about the theological positions on sexual diversity in Hinduism, Sikhism and Islam, the three most significant religious groups in the South Asian diaspora (Jhutti-Johal, 2011; Kugle, 2010), individuals may use religious imagery in order to substantiate the view that it is impossible to be gay and of religious faith (Jaspal, 2012). Such religious representations may be uncritically accepted by British South Asians of all sexual identities. Furthermore, gay men from these communities may experience exclusion from ethnic and religious ingroups due to homonegative stigma.

The psychological effects of such stigma for British South Asians can be profound. In one of the first studies of identity among BSAGM, Bhugra (1997) noted feelings of regret, selfdeprecation and self-hatred in his participant sample, which was attributed to the 'traumatic discrepancy' between ethnicity and sexuality, and referred to participants' unsuccessful attempts to construct 'a coherent sense of self from the two identities he seeks to attain: Asian and gay' (p. 556). Furthermore, research shows that ethnic minority gay people, including BSAGM, are at increased risk of depression, psychological distress and self-harm due to situational stressors, such as rejection from their family and culture (Jaspal, Lopes \& Rehman, 2019; Rehman, Lopes \& Jaspal, 2020). It is noteworthy that individuals may also face racism in gay affirmative social contexts, leading to an additional layer of exclusion and threats to their sense of belonging in a space in which they seek acceptance and inclusion (Bassi, 2008; Jaspal, 2017).

These studies, though valuable in enhancing our understanding of social and psychological wellbeing among BSAGM, do not shed light on social representations of Britishness in this population. This is a significant lacuna in existing knowledge on the South Asian diaspora, which, if addressed, may enable us to understand their level of access to a British national identity - a potential source of group identification, social support and psychological wellbeing (Sani et al., 2012).

\section{Social representations of Britishness}

Social representations theory (Moscovici, 1988) focuses on the construction of 'common sense' knowledge, that is, how people make sense of complex, esoteric phenomena that become relevant to their lives. According to the theory, a social representation can be conceptualised as a collective 'elaboration' of a given social object which enables people to think and talk about it. Moreover, social representations shape behaviours in relation to this object. This includes abstract constructs, such as British national identity (that is, what it means to be British; who is and is not deemed to be British; and its compatibility with other identities). Specifically, two principal social psychological processes converge in the creation of social representations:

- anchoring refers to the process of linking a novel, unfamiliar phenomenon to something that that is familiar and known to us. For instance, Britishness may be anchored to images of its imperial past, leading people to disassociate it from their identities (Kumar, 2000). 
- objectification refers to the process whereby an abstract phenomenon is rendered concrete and tangible - especially through the use of metaphors and symbols.

In this study, there is a focus on the ways in which anchoring facilitates particular social representations of Britishness among BSAGM. Drawing on the work of Vadher and Barrett (2009), which identifies six 'boundaries' of Britishness, we identify how these are transformed into social representations and how they subsequently shape the individual's self-concept. The advantage of viewing the boundaries in terms of social representations is that this approach acknowledges the flexibility and variability of notions of Britishness in accordance with social context.

In her theoretical synthesis of social representations and identity, Breakwell (2014) has outlined how individuals respond to social representations in their social context. Individuals differ in the extent to which they are aware of, understand, accept, and assimilate to their selfconcept a social representation. For instance, although an individual may be aware of the imperial representation of Britishness, they may not really understand it because of their limited knowledge of British imperial history. Nevertheless, salient aspects of that representation may determine the extent to which they see themselves as British. If the individual accepts and assimilates to their self-concept a given social representation of Britishness, it will determine the extent to which they self-identify with this social category as well as the perceptions and relations with others whom they do and do not perceive as British.

\section{Participants}

\section{Methods}

Using a snowball sampling strategy, fifteen self-identified BSAGM were recruited in the East Midlands region and in West London in England. Eight participants were of Indian background and identified as Hindu or Sikh, and seven were of Pakistani background and self-identified as Muslim. They all described themselves as either religious or moderately religious and were active in their respective religious communities. Participants were aged between eighteen and thirty-three years. Nine participants had received, or were studying towards, a university degree, and six had completed college education. All of the interviewees reported being single. Three participants described themselves as being completely open about their sexual identity; six as open to some people; and six as being open only to other gay people.

\section{Analytic approach}

The data were subjected to qualitative thematic analysis, which has been described as 'a method for identifying, analyzing and reporting patters (themes) within data' (Braun \& Clarke, 2006, p. 78). When used in conjunction with social representations theory, it enables the analyst to examine the content and structure of social representations (in this case, of Britishness) and their utility in relation to identity construction (as BSAGM). In this study, thematic analysis was used to identify themes in the interviews concerning conceptualisations of Britishness and how they in turn shape the construction and management of national, ethnic and sexual identities in the face of competing pressures (e.g. racism, homophobia). A realist epistemological stance was employed and, accordingly, participants' discourse in interviews was considered a reflection of underlying cognitions.

\section{Research procedure}

The interviews were guided by a semi-structured schedule consisting of twelve exploratory, open-ended questions, which focused on the following topics: understanding of what it means to be British, aspects of British national identification, experiences of coming out as gay, and relationships with other people (especially White British gay men). Interviews lasted between 60 and 70 minutes. They were digitally recorded and transcribed verbatim. 
During each reading of the interview transcripts, preliminary interpretations were noted in the left margin, which included inter alia participants' meaning-making, particular forms of language, apparent contradictions, and patterns of meaning in the data. At the next step, the right margin was used to collate these initial codes into potential themes, which captured the main characteristics of the accounts - with the original research questions in mind. The list of themes was reviewed rigorously against the data in order to ensure their compatibility and numerous interview extracts were listed against each corresponding theme. At this stage specific interview extracts, which were considered vivid, compelling and representative of the themes, were selected for presentation in this article. Finally, three superordinate themes representing the analysis of participants' accounts were developed and ordered into a logical and coherent narrative structure. In the interview extracts presented in the next section, three dots indicate where material has been excised and other material within square brackets is for clarification.

\section{Results}

In this section, the following three superordinate themes, which summarise the thematic analysis are described: (1) the racial representation and exclusion, (2) the multicultural representation and variable belonging, and (3) the civic/ instrumental representation and multifaceted belonging.

\section{The racial representation and exclusion}

Some interviewees anchored Britishness to White British ancestry, thereby positioning only White British people are 'true' Britons. Crucially, in most cases, the racial representation of Britishness was exclusionary and perceived as being consensually accepted by the White British majority and, thus, imposed on them as minority individuals (of South Asian ethnicity):

No matter how hard you try, you're never really one of them because you're not White. Even if it's for something good 'oh you can get into Oxford because they want more brown people' or for something bad it's like 'you Paki this, you Paki that'. It's like you're not really part of them, like British, because you're not White. (Salim, Pakistani, 20)

My parents always said it to me too 'you're not accepted by them as British because you're Asian'. For them we're Asians, we're Muslims, not really British. I've tried to fit in but you just can't no matter what. They don't let you in. (Zee, Pakistani, 25)

Salim and Zee referred to the distinct ways in which they felt excluded from the category of Britishness, noting both overt denigration and exclusion (using slurs such as 'Paki') but also 'positive discrimination' which nonetheless made them feel excessively distinctive and that they did not belong in mainstream British society. Interviewees frequently observed that their parents had resigned themselves to the 'fact' that South Asians would never be accepted by White British people but that, as second and third generation British Asians, they had attempted to carve a space within, and lay claim to, Britishness. Despite his attempts to 'fit in', Zee reported accepting the racial representation and reaching the conclusion that his parents were in fact right. Like many participants, Zee accepted this representation due to first-hand experiences of negative contact with the White British majority. It is noteworthy that British Pakistani Muslim participants appeared to accept the racial representation more readily than British Indian participants, which could be attributed to perceived Islamophobia in Britain - an additional layer of exclusion from Britishness (Allen, 2010): 
I reckon it's harder for, for us I mean Muslims because firstly they say 'Paki' so they mean us and then you know it's all these fanatics like ISIS jokes and 'will you get chucked off a building [for being gay]?' and that so they think all Asians are not part of them but mostly us really, especially Muslims. (Saeed, Pakistani, 28)

In line with the racial representation of Britishness, Saeed and others believed that their exclusion from the category of Britishness was attributable to their ethnic identity, as nonWhite individuals. However, there was a pervasive belief among Muslim interviewees that they were especially vulnerable to the negative effects of the racial representation due to their stigmatised religious identity (as Muslims) and the negative imagery surrounding the treatment of gay people in Islam. Saeed exemplified this by drawing on the social representation that Islam is invariably opposed to sexual diversity, noting the brutal execution of gay people in Islamic State of Iraq and the Levant (ISIL)-controlled territories. Like Saeed, several interviewees referred to use of such imagery to argue against the Britishness of Asians, and especially that of Muslims, and thus to exclude them further. Crucially, they reported first-hand exposure to such imagery in their interactions with others, which led them to accept this social representation of Britishness.

Participants were invited to discuss their social representation of Britishness in relation to social contexts in which their sexual identity (as gay men) was salient, such as in gay affirmative contexts:

Aaron (Indian, 18): It don't matter where you are, it's all the same, really. At work you stick out, in gay clubs you're ignored, on apps ${ }^{1}$ I get all kind of abuse and I'm not seen as one of them.

Interviewer: Could you give me a specific example of this?

Aaron: I get introduced. If he's White, he's like thinking 'where are you from? No, I mean, like really from?' It creates a distance.

On Grindr you get what people really think because they can say what they really think and then just block you...Sometimes I get guys telling me they're not into me because they're looking for someone British, and last time I checked I was, but yeah they mean White so it's the same thing in their head for most of them. (Abdul, Pakistani, 26)

Some interviewees believed that the racial representation of Britishness was pervasive across various social contexts, including the work environment in which non-White people were conspicuously distinctive and in gay clubs in which they felt ignored. This suggested that the racial representation did not allow individuals to achieve optimal distinctiveness across the various social contexts in which they interacted with White British people, that is, an optimal sense of belonging (acceptance and inclusion) and distinctiveness (Brewer, 1993).

The anchoring of Britishness to White British ancestry was pervasive across the interviews - Aaron referred to the common question 'where are you from?' which suggested that his non-White ethnicity indicated his 'otherness'. Both Aaron and Abdul referred to the abuse and hostility that they encountered from White British gay men in relatively anonymous online forums, such as on gay social networking applications, where the 'true' perceptions of White British people were reportedly easier to gauge. More specifically, some interviewees believed that the anonymity of online applications provided a more accurate indicator of what the White British thought of them, potentially leading these interactions to inform their social representation of Britishness as a racialised category. Indeed, Abdul reported rejection on gay

\footnotetext{
${ }^{1}$ Gay mobile social networking applications, such as Grindr and Scruff.
} 
social networking applications from White British gay men who were reportedly 'looking for someone British'. 'British' was perceived as synonymous with whiteness, which led participants to anchor Britishness to race in this way. The key point is that all of the interviewees were British but did not feel accepted as such due to their South Asian ethnicity, which made national identity less accessible to them.

The racial representation of Britishness appeared to cause negative social and psychological outcomes among interviewees, especially in their interactions with other gay men:

I kind of get anxious when I'm about to go out because I'm thinking the bouncer [at a club] won't let me in because I'm not one of them or I'll get funny looks or people will try to single me out or whatever. (Saeed, Pakistani, 28)

When I go on Grindr, I'll think twice about sending my face to a White guy and just test the waters because you can bet money on what they'll reply, what their reply is going to be. (Aaron, Indian, 18)

They just think 'foreigner', so scary and that doesn't feel so good because you like end up thinking 'is there something up with me?' or like 'what's wrong with me?' I'm just as British as them. (Suraj, Indian, 25)

Like Saeed, several interviewees exhibited hypervigilance in relation to the White British majority and their accounts suggested that there may be an element of paranoia, that is, irrational suspicion about others' intentions and that they might be attempting to cause harm. Indeed, Saeed referred to his fear that others may give him 'funny looks' or try to 'single him out' because of his ethnicity. Due to the racial representation of Britishness, he did not expect to be included or accepted on the gay scene. Similarly, Aaron was hypervigilant about the responses of White British gay men in online forums and anticipated rejection from them. This led him to conceal his ethnicity from other users. There was a common thread in the accounts of interviewees who accepted the racial representation of Britishness, namely that they believed that they were viewed by others as 'foreign' (despite their British citizenship) and, thus, treated with suspicion and hostility. Suraj's account captured the deleterious impact of the racial representation (and its associated factors) not only on their sense of belonging but also selfesteem.

\section{The multicultural representation and variable belonging}

There was evidence of a multicultural representation of Britishness among some interviewees. They generally anchored Britishness to ethnic, cultural and religious plurality, challenging the notion of a monolithic British culture:

England's not been this single culture. My mum was telling me that theirs was the first Asian shop in the area but then they started coming in and people got used to it so today it's like 'which is the White house on the street' (laughs)...There's a melting pot of cultures and that and that's the new 'British'. (Raj, Pakistani, 28)

When I think 'British', I think about curry, Black and White people in the same neighbourhood. Even the whole empire thing was about mixing people so anyone can be British and I don't think that says nothing about your race or that. That's why they say 'British Asian' 'British Hindu' and that because it's OK to be both. (Baljit, Indian, 31) 
This is a diverse country and each culture has its respect and its way of doing stuff...For me, the test is you walk down the street speaking Punjabi and nobody looks your way. That means, you're just part of the background and nobody cares. You're British. I am British but more British Pakistani. (Farhad, Pakistani, 27)

For interviewees who accepted the multicultural representation of Britishness, the nation evoked ethnic diversity, the possibility of White British people as minorities in some contexts, South Asian cuisine, and linguistic diversity. They observed that significant demographic change (mainly through migration) has resulted in a new conceptualisation of Britishness but there was also an acknowledgement that, even in the days of the British Empire, there had been a proclivity to 'mix people'. The roots of multiculturalism were, thus, understood to be longstanding. The multicultural representation removed race and ethnicity as possible barriers to Britishness given that national identity was defined by diversity, rather than curtailed by it. This in turn enabled individuals (such as Baljit and Farhad) to identify with hybrid categories prefixed by 'British', such as 'British Asian' and 'British Pakistani'. Individuals who accepted the multicultural representation did not feel excluded by White British co-nationals, reporting that they had become 'part of the background'. As Vadher and Barrett (2009) argue, the multicultural conceptualisation of Britishness is the most inclusive of all and generally enables individuals to access a British national identity.

Unlike the racial representation, the multicultural representation also enabled some, mainly British Indian, interviewees to derive a sense of acceptance and inclusion from White British gay men in gay affirmative social contexts:

I was in a pretty bad place [in relation to sexuality] and started to go out and, you know, meeting up with guys and I made some pretty strong friendships with guys who sort of like showed me another way of living and being more confident in myself. I felt pretty accepted, yeah. I got a boyfriend, a White guy and he - we're not together now he was my lifeline then. (Arjun, Indian, 30)

Yeah, most of my gay mates are White and I don't think there's much racism personally. I don't get it myself but then I've always been a bit of a coconut, I suppose (laughs) but I do think they get that some of us ain't White and that's fine, we're still British. It's an open country after all. (Sukhy, Indian, 25)

In hindsight, Arjun construed his friendships and relationships with White British gay men as providing much-needed psychological and emotional support when he came out as gay, which was a psychologically challenging experience due principally to parental rejection. Because he accepted the multicultural representation of Britishness, Arjun felt able to derive not only acceptance and inclusion from co-nationals but also alternative social representations of his sexuality. In other words, he was able to perceive his sexuality in novel ways - other than through the lens of his ethnicity and religion. This reportedly provided greater feelings of selfconfidence and a more positive relationship with his sexuality. Individuals who accepted the multicultural representation did not generally believe themselves to be rejected due to their ethnicity although Sukhy did refer to himself as a 'coconut' - a racialised term used to refer to British South Asians who share more cultural similarities with White British people than with their ethnic group despite their non-White appearance (Kim, 2014). Nonetheless, participants did report a sense of belonging and, in some cases, described their relationships with White British gay men as providing psychological respite from the challenges they faced in their respective ethnic and family contexts. 
However, a less favourable dimension of the multicultural representation was the perceived tolerance and acceptability of overt homophobia in South Asian communities. More specifically, some interviewees believed that multiculturalism was 'excessively tolerant' and, thus, permitted all cultural norms, including those that stigmatised and denigrated sexual minorities:

The whole thing about accepting and respecting cultures and that is all good but then they don't really to understand it. It's more like 'let them get on with it' and I reckon it's more of an excuse to not care. (Mo, Pakistani, 31)

I think we should raise awareness of what we go through as gay Asians, in our community here. (Zee, Pakistani 25)

There's got to be more policing of rights and more efforts to work with the Asian community about changing their opinions about being gay and that. But there isn't. (Ali, Pakistani, 33)

When I came out my parents...my parents tried to keep me in the house, took my phone and tried to get me married off and I tried to reach out and it was a bit like 'is there any violence?' no, so you could tell they're thinking we've got a weird culture and they don't want to get involved in it. (Karan, Indian, 30)

Several respondents described the perceived risk associated with multiculturalism that state institutions (such as the justice system) might not acknowledge, and attempt to address, homophobia in South Asian communities, which respondents unanimously acknowledged facing in their lives. Like Zee, most interviewees reported a need for greater awareness and understanding of the specific psychological and cultural challenges faced by BSAGM. Yet, they believed that the multicultural representation of Britishness, which is inclusive of cultural diversity, may preclude positive engagement with specific communities concerning their attitudes towards, and treatment of, sexual minorities.

There was a perception that this conceptualisation of Britishness led to unchecked persecution of sexual minorities within their communities. For instance, Karan was one of several interviewees who had been coerced into an arranged heterosexual marriage reportedly to 'cure' his sexuality. Some individuals did not feel comfortable seeking institutional support with challenges of this kind because they believed that there was insufficient understanding of these issues at the institutional level and that multiculturalism caused scepticism about intervention from the authorities. This is consistent with the culture of 'political correctness' which Vadher and Barrett (2009) observed in relation to the multicultural boundary. In short, there was a perception that, while inclusive, multiculturalism encouraged disengagement from state institutions in relation to potentially harmful practices, such as homophobia and forced marriage, and thus an uninhibited continuation of such practices.

Finally, it is noteworthy that representations of Britishness also operated in a contextspecific manner - interviewees perceived representations to operate in some contexts but not in others. Crucially, some believed that multiculturalism did not function in the same way on the gay scene and that, unlike in mainstream British society, among gay men there was a stigmatisation of ethnic diversity: 
I like the diversity in this country like vindaloo, watching East is East ${ }^{2}$ and that and it makes you feel like you contribute to this society and you're like valued and being an Asian is good...I just wish there were more of it when you're out on the [gay] scene but there isn't. In a way that's a more racist place-gay people are I mean, but outside it's $O K$. (Karan, Indian, 30)

Gay clubs are not multicultural-friendly, I find. (Arjun, Indian, 30)

There was perceived acceptability of racism in gay affirmative social contexts, such as gay bars and clubs, in that White British gay men reportedly expressed racism in more socially acceptable ways, that is, through the discourse of sexual preference and desire. This led individuals to feel excluded from the national category, curtailing feelings of belonging. This behaviour, though reportedly prevalent in gay affirmative social contexts, was deemed to be inconsistent with the multicultural representation of Britishness.

\section{The civic/ instrumental representation and multi-faceted belonging}

Some participants anchored Britishness to civic aspects of national identity, such as having a passport, being born in the country, and contributing to civic society, and to the perceived practical benefits of the national identity:

I do feel British to be honest and it's because of my passport. It says British. I've got the same right as everyone else and that's who I am. If someone doesn't accept me then fine, it's up to them as far as I'm concerned...I've got the same rights as anyone else, same education, same healthcare, same job rights, same everything...I'm an Indian by origin but you know, if you're Indian or whatever, you're still British. (Parmjit, Indian, 21)

If we were in India, we wouldn't be able to do what we do and be exactly who you are...Money talks there. Here it's every citizen is equal so the equality of a big part of being British, not Indian. (Sukhy, Indian, 25)

You come here and can be known as British and anyone can be if you accept the main thing and it's freedom... But then you keep your culture at home and it's not a bad thing actually. (Salim, Pakistani, 20)

Both the civic and instrumental aspects of Britishness rendered this national identity available to individuals with a British passport. Interviewees emphasised shared rights, equality and freedom in their conceptualisation of Britishness (using this social representation), which were values that they unanimously espoused. Therefore, they could and did perceive themselves to be British. However, as Parmjit and Salim indicated, the civic/instrumental representation did not always permit overt expressions of ethnic identity but emphasised the 'core values' of Britishness - however these values might be defined. In view of the psychological significance of ethnic identity for many people of South Asian descent, this representation was not consensually accepted by all participants - especially those whose principal source of identification was their ethnic ingroup. However, a key advantage for individuals who did accept this social representation was that it enabled them to integrate their sexuality in their self-concept:

\footnotetext{
${ }^{2}$ East is East is a 1999 British comedy film about a mixed heritage British Pakistani family in Northern England in the 1970 s.
} 
Being British is a lifeline for me. Maybe I didn't really care that much as a kid but when I came out I did realise that yes I do have another thing to turn to and that's my rights. If I was in India and came out to my parents there, would I be able to live my life? No way. (Baljit, Indian, 31)

I'm gay and I'm Asian and I'm British and I've felt like I can be all of that in this society but not everywhere. I can switch between these things and none of them stop me from doing what I need to do, if I'm smart about it. (Suraj, Indian, 25)

I reckon if we had a system where you know you do X and it's wrong and even if it's right in your culture, it ain't here so you're in trouble. (Karan, Indian, 30)

Although the instrumental aspects of Britishness have generally been discussed in terms of access to public services (e.g. Vadher \& Barrett, 2009), interviewees in our study described the instrumentality of Britishness in enabling them to cope with the challenges associated with their sexuality, including coming out. They believed that, because of their British citizenship, they were protected by British human rights law and were therefore able to 'live out' their sexual identities in a way that would not have been possible in their ethnic homelands - a comparison frequently made by interviewees. This should be contrasted with the multicultural representation which reportedly put BSAGM at risk of cultural norms prohibitive of their sexuality.

Indeed, Karan noted that the civic/instrumental conceptualisation of Britishness would foreground its core values and enable people to question and oppose cultural norms deemed to be incompatible with these values. He was referring to homophobia in South Asian communities, which many who accepted this representation construed as 'un-British'. Moreover, the civic representation of Britishness was understood to prioritise Britishness (defined much more broadly and inclusively than the racial representation) over other identities, although these identities could still be retained and manifested. In other words, the civic/instrumental representation did not exclude people due to these other identities. This social representation of Britishness also enabled individuals to 'switch' between identities in accordance with social context, thereby enabling them to retain identity multiplicity.

Identity multiplicity was important to most interviewees who did not wish to assimilate to 'British culture' and potentially lose their valued ethnic identity. They wished to retain both national and ethnic identities and also the flexibility to draw on these identities in accordance with social context:

I feel OK. I don't think there's much of an issue. My parents know who I am but I'm not going to advertise it with them...I blend in with White people and I blend in with Asians. It's just about keeping it simple and being sensible about it. (Sukhy, Indian, 25)

If I didn't have my culture to fall back on, yeah, I'd be a bit lost I suppose (laughs). I'm not British. I'm British Asian. (Zee, Pakistani, 25)

Interviewees pervasively noted the psychological significance of their ethnic and religious identities, which they wished to retain alongside their British national identity. The civil/instrumental representation of Britishness enabled some of them to deploy identity aspects, such as ethnicity and religion, in accordance with social context. This conceptualisation of Britishness did not exclude them prima facie provided that they adhered to a set of common values central to Britishness. Moreover, it facilitated an instrumental view 
of their national identity because it served important functions - not only economic but also psychological in that it enabled them to embrace the multiplicity of their identities and to withstand ethnic and religious pressures to relinquish their sexuality.

\section{Discussion}

The purpose of this study was to examine social representations of Britishness and their social psychological impact for BSAGM who are constructing an identity that comprises nationhood, ethnicity, religion and sexuality. This study identifies three main social representations of Britishness among BSAGM: the racial, multicultural and civic/instrumental representations, which are broadly consistent with the boundaries of Britishness outlined in earlier research (Jacobson, 1997; Vadher \& Barrett, 2009). These representations are formed in conjunction with other people (such as through conversations with one's parents) and through first-hand experiences in various contexts (such as in the workplace and in gay affirmative social contexts). Some interviewees anchored Britishness to race and ancestry (racial), while others anchored it to ethnic, cultural and religious plurality (multicultural), or to civic elements which reportedly perform positive functions for the group or individual (civic/instrumental).

These social representations were characterised by fluidity and variability, and fluctuated in accordance with social context in that it was possible to accept a particular representation of Britishness in one context (e.g. in the workplace) but to adopt another in a different context (e.g. in a gay bar). Furthermore, not every individual espoused a single representation of Britishness, further exemplifying the variability of this construct. As Cohen (2000, p. 582) stated, identities 'are contingent and situational (one can be Muslim in the mosque, Asian in the street, Asian British at the political hustings and British when travelling abroad, all in a single day).' Here it is argued that distinct social representations, which are also contingent and situational, support these shifting identities.

As indicated in Breakwell's (2014) overview of 'personalising' social representations, interviewees varied in the extent to which they were aware of, understood, and accepted social representations of Britishness - a small minority were unaware of the racial representation and therefore were not affected by it, while most reported awareness of it. Moreover, some respondents were aware of the racial representation but did not accept it and instead favoured another, such as the civic representation, which in turn enabled them to access a British national identity. Various factors determine the likelihood of accepting any given social representation of Britishness - interviewees referred to personal experiences which 'confirmed', in their minds at least, the accounts of their parents (e.g. that South Asians would never be British). Once accepted, each social representation has distinct implications for perceived inclusion in the national, ethnic and sexual ingroups and determines the perceived level of access to these social group memberships.

Although there is overlap in the boundaries of Britishness identified in earlier research (Jacobson, 1997; Vadher \& Barrett, 2009) and those described here, their operation at social and psychological levels are different for BSAGM. The racial representation of Britishness was widespread in the interviews, especially among British Pakistani Muslim interviewees. This may be attributed to increased levels of Islamophobia in society (see Allen, 2010). Although the study design did not allow us to identify systematic differences between British Indian and British Pakistani respondents, the results did suggest that the insidious effects of Islamophobia reinforced the racial representation of Britishness, on the one hand, and reduced access to the multicultural representation, on the other hand. British Pakistani interviewees did not generally feel that they were accepted due to their Muslim identity, in particular, and that there was hostility towards them from the White British majority. These perceptions and experiences led them to believe that they would never be accepted due to a racial representation of Britishness. 
Interviewees expressed this social representation in distinct ways and exemplified it by drawing on their own personal experiences of stigma and prejudice - some subtle, others overt. A common thread throughout all of these accounts was the perception that Britishness was synonymous with whiteness, which thus excluded them from genuine acceptance and inclusion within this social category. Crucially, the racial representation also deprived individuals of a potential source of social support, namely from White British gay men, in the face of homophobia reported within their ethnic ingroup. There is evidence of the psychological sequelae of homophobic rejection and hostility from the ethnic ingroup (e.g. Jaspal, Lopes \& Rehman, 2019) and of racism from others on the gay scene (Jaspal, 2017). Devoid of social support from their ethnic ingroup or sexual ingroup (i.e. other gay men men), individuals who accept the racial representation of Britishness may be at greater risk of social and psychological adversity because they may become socially isolated.

The multicultural representation was more common among British Indian Hindu and Sikh interviewees and was construed as the most inclusive approach to nationhood (Vadher \& Barrett, 2009). However, it was generally less accessible to British Pakistani interviewees. This representation was especially important for those interviewees who valued their ethnic identity, wished to retain a connection with it and manifest it publicly (Cinnirella \& Hamilton, 2007). However, there were distinct understandings of this representation. Some perceived the multicultural representation to be pervasive in British society due to the (positive) impact of migration and also felt accepted by White British gay men with whom they shared a superordinate British national identity. Others believed that this representation did not operate in gay affirmative social contexts (e.g. bars, clubs) and, thus, they could not derive a sense of belonging within these spaces. They often referred to 'sexual racism' and the ease with which it was expressed through the more socially acceptable discourse of sexual preference (Callander, Holt \& Newman, 2012).

Yet, a significant challenge associated with the multicultural representation in our participant sample was the perception that multiculturalism had led to excessive 'political correctness' which meant that cultural and religious homophobia and some harmful traditional practices (e.g. forced marriage) might go unchallenged (Idriss, 2019). There was a common view among interviewees that there was institutional trepidation about intervening to challenge such practices lest this cause offence in the context of multiculturalism. In view of the personal experiences of cultural pressure, honour abuse, and forced marriage narrated by interviewees, the multicultural representation of Britishness caused fear for the future - some believed that it would be difficult to obtain institutional support (associated with Britishness) if this became necessary. This was distressing for some who hoped for greater institutional protection for nonheterosexual people from ethnic minority backgrounds. In short, the multicultural representation appears to be associated with an inconsistent sense of belonging in the minds of both British Indian and British Pakistani respondents.

There was evidence of a civic/instrumental representation of Britishness, which was deemed to be inclusive of diversity provided one comply with some civic conditions, such as having a British passport, having been born in the United Kingdom and adherence to a limited set of shared 'British values'. Interviewees did not perceive this form of national identity to be competing with their ethnicity or religion, thereby suggesting inclusivity. Moreover, the civic representation provided the flexibility to shift between identities in different contexts without risking one's sense of belonging (see Cohen, 2000). Some interviewees derived feelings of identity security in view of the civic/instrumental representation because they felt accepted and included in the national category, able to access social support from other gay men (including those of White British ethnicity), and secure in the knowledge that they could retain a connection with their ethnic group but contest homophobic practices within it, if necessary. Not all of the interviewees believed that this representation of Britishness was, as yet, 
accessible but expressed hope that it would be accepted, endorsed and promoted in the future, thereby enabling them to self-identify authentically.

The civic/instrumental social representation was empowering for those interviewees who accepted it, principally because it supported the multiplicity and coherence of identity among BSAGM. It is noteworthy that, while in their study of young British South Asian adults, Vadher and Barrett (2009) describe civic and instrumental conceptualisations as two distinct 'boundaries', we refer to it as a single social representation. The civic aspects of nationhood were described in terms of their utility and functionality for identity. In other words, Britishness was accessible because of citizenship and because it served important functions for identity principally identity coherence, belonging, and social support. Indeed, individuals are more likely to prioritise those identities (e.g. Britishness) that serve important functions for the selfconcept (Vignoles et al., 2011). Therefore, it is appropriate to consider the civic and instrumental aspects of nationhood as a unified social representation.

\section{Limitations}

This social psychological study of Britishness among BSAGM has some limitations which should be addressed in future research. First, the study was conducted in England and should be replicated in other parts of the United Kingdom, such as Scotland, where Britishness may be a less significant identity than Scottishness. Second, the study did not examine issues of social class, which are likely to impinge on national identification. This should constitute the focus of future work in this area. Third, the issue of national identification should be examined from other disciplinary perspectives to complement the social psychological analysis presented here. For instance, although this is not a study of nationalism but of self-identification with various social identities (as well as nationhood), the concept of homonationalism (Puar, 2013) from gender studies may enrich scholarly debates about national identity among BSAGM.

\section{Conclusions}

Social representations of Britishness are complex, nuanced and context-specific. They vary in their structure and evolve over time. They become salient in the minds of individuals as a result of societal events and psychological states. Crucially, social representations of Britishness determine who can and cannot access a British national identity. Our findings suggest that the racial representation is aversive for belonging, identity coherence and self-esteem and that it should be actively challenged at all levels. The multicultural representation, while inclusive for some, is potentially divisive and can lead to a less secure self-concept (especially in relation to sexual identity). This study suggests that a civic/instrumental representation of Britishness is most inclusive of all and facilitates national identification among those BSAGM who desire it. The representation enables individuals to shift between multiple identities freely, to derive a sense of belonging within various social spheres, and to challenge discourses that undermine valued identities (such as sexuality). It acknowledges that a robust national identity performs positive functions - not only practical but also social and psychological.

\section{Declaration of interest statement}

The authors have no interests to declare.

\section{Notes on contributors}

Rusi Jaspal is Professor of Psychology at Nottingham Trent University, UK. He is the author or editor of six books and more than 100 journal articles and book chapters, focussing mainly on the social psychological aspects of identity. Rusi Jaspal is the author of 'The Social Psychology of Gay Men’ (Palgrave, 2019). 
Razina Ferozali is a PhD student in Psychology at Nottingham Trent University, UK. Her doctoral research focuses on the impact of cultural honour on identity and psychological wellbeing among British South Asians.

\section{References}

Allen, C. 2010. Islamophobia. London: Ashgate.

Ballard, R. 1994. Desh Pardesh: The South Asian Experience in Britain. London: C. Hurst.

Bassi, C. 2008. "The Precarious and contradictory moments of existence for an emergent British Asian gay culture," in New Geographies of Race and Racism, eds. Claire Dwyer and Caroline Bressey (London: Routledge), 209-222.

BBC (2020). British Asians 'more socially conservative'. BBC News. https://www.bbc.co.uk/news/uk-45133717

Bhugra, D. 1997. Coming out by South Asian gay men in the United Kingdom. Archives of Sexual Behaviour 26: 547-557.

Breakwell, G.M 2014. The Psychology of Risk. Cambridge: Cambridge University Press.

Brewer, M.B. 1993. "The role of distinctiveness in social identity and group behaviour," in Group Motivation: Social Psychological Perspectives, eds. Michael Hogg and Dominic Abrams (Harvester Wheatsheaf), 1-16.

Burholt, V. Dobbs, C. and Victor, C. 2016. Transnational relationships and cultural identity of Oolder migrants. Geropsych 29(2): 57-69.

Callander, D. Holt, M. and Newman, C. E 2012. Just a preference: racialised language in the sex-seeking profiles of gay and bisexual men. Culture, Health \& Sexuality 14(9): 1049-1063.

Cinnirella, M. 1997. Towards a European identity? Interactions between the national and European social identities manifested by university students in Britain and Italy. British Journal of Social Psychology 36(1): 19-31.

Cinnirella, M. 2014. "Understanding Islamophobic prejudice: the interface between Identity Process Theory and Intergroup Threat Theory," in Identity Process Theory: Identity, Social Action and Social Change, ed. Rusi Jaspal and Glynis Breakwell (Cambridge: Cambridge University Press), 253-269.

Cinnirella, M. and Hamilton, S. 2007. Are all Britons reluctant Europeans? Exploring European identity and attitudes to Europe among citizens of South Asian ethnicity. Ethnic and Racial Studies 30(3): 481-501.

Cohen, R. 2000. The incredible vagueness of being British/English (review article). International Affairs 76: 575-582.

Dwyer, C. 2000. Negotiating diasporic identities. Women's Studies International Forum 23(4): 475-486. 
Ghuman, P. 2003. Double Loyalties. Cardiff: University of Wales Press.

Hussain, Y. and Bagguley, P. 2005. Citizenship, ethnicity and identity. Sociology 39(3): 407425 .

Idriss, M.M., ed. 2019. Men, Masculinities and Honour-Based Abuse. London: Routledge.

Jacobson, J. 1997. Religion and ethnicity: dual and alternative sources of identity among young British Pakistanis. Ethnic and Racial Studies 20: 238-256.

Jaspal, R. Lopes, B. and Rehman, Z. 2019. A structural equation model for predicting depressive symptomatology in Black, Asian and Minority Ethnic gay, lesbian and bisexual people in the UK. Psychology \& Sexuality. Advance online publication. doi: 10.1080/19419899.2019.1690560.

Jaspal, R. 2012. 'I never faced up to being gay': sexual, religious and ethnic identities among British Indian and British Pakistani gay men. Culture, Health \& Sexuality 14(7): 767-780.

Jaspal, R. 2015. Migration and identity processes among first-generation British South Asians. South Asian Diaspora 7(2): 79-96.

Jaspal, R. 2017. Coping with ethnic prejudice on the gay scene: British South Asian gay men. Journal of LGBT Youth 14(2): 172-190.

Jaspal, R. 2020. Parental reactions to British South Asian young men who identify as gay. Journal of GLBT Family Studies 16(4): 402-417.

Jaspal, R. and Cinnirella, M. 2010. Coping with potentially incompatible identities: accounts of religious, ethnic and sexual identities from British Pakistani men who identify as Muslim and gay. British Journal of Social Psychology 49(4): 849-870.

Jaspal, R. and Cinnirella, M. 2012. The construction of ethnic identity: insights from identity process theory. Ethnicities 12(5): 503-530.

Jaspal, R. and Cinnirella, M. 2013 The construction of British national identity among British South Asians. National Identities 15(2): 157-175.

Jaspal, R. and Siraj, A. 2011. Perceptions of "coming out" among British Muslim gay men. Psychology and Sexuality 2(3): 183-197.

Jhutti-Johal, J. 2011. Sikhism Today. London: Continuum.

Kelman, H. C. 1997. "Nationalism, patriotism, and national identity: social-psychological dimensions," in Patriotism in the lives of individuals and nations, ed. Daniel Bar-Tal and Ervin Staub (Chicago, IL: Nelson-Hall), 165-189.

Kiely, R., McCrone, D. and Bechhofer, F. 2005. Whither Britishness? English and Scottish people in Scotland. Nations and Nationalism 11(1): 65-82. 
Kim, H. 2014 'No caps, no coconuts, no all-male groups' ... the regulation of Asians in London clubs. Ethnic and Racial Studies 37(4): 636-651.

Kugle, S.S.H. 2010. Homosexuality in Islam: Critical Reflection on Gay, Lesbian, and Transgender Muslims. Oxford: Oneworld.

Kumar, K. 2000. Nation and empire: English and British national identity in comparative perspective. Theory and Society 29(5): 575-608.

Manning, A, and Roy, S. 2010. Culture clash or culture club? National identity in Britain. The Economic Journal 120(542): F72-F100.

Maxwell, R. 2009. Caribbean and South Asian identification with British society: the importance of perceived discrimination. Ethnic and Racial Studies 32(8): 1449-1469.

Maxwell, R. 2006. Muslims, South Asians and the British mainstream: A national identity crisis? West European Politics 29(4): 736-756.

Modood, T. 2005. Multicultural Politics. Edinburgh: Edinburgh University Press.

Moscovici, S. 1988. Notes towards a description of social representations. European Journal of Social Psychology 18: 211-250.

Puar, J. 2013. Rethinking homonationalism. International Journal of Middle East Studies 45(2): 336-339.

Rehman, Z. Lopes, B. and Jaspal, R. 2020. Predicting self-harm in an ethnically diverse sample of lesbian, gay and bisexual people in the United Kingdom. International Journal of Social Psychiatry 66(4): 349-360.

Robinson, L. 2009. Cultural identity and acculturation preferences among South Asian adolescents in Britain: an exploratory study. Children \& Society 23(6): 442-454.

Sani, F. Herrera, M. Wakefield, J. Boroch, O. and Gulyas, C. 2012. Comparing social contact and group identification as predictors of mental health. British Journal of Social Psychology 51(4): 781-790.

Sekhon, Y. K. and Szmigin, I. 2011. Acculturation and identity: insights from secondgeneration Indian Punjabis. Consumption Markets \& Culture 14(1): 79-98.

Smith, A. D. 1991. National Identity. London: Penguin Books.

Smith, A. D. 1998. Nationalism and Modernism. London: Routledge.

Spinner-Halev, J. and Theiss-Morse, E. 2003. National identity and self-esteem. Perspectives on Politics 1(03): 515-532.

Tajfel, H. and Turner, J.C. 1986. "The social identity theory of intergroup behaviour," in Psychology of Intergroup Relations, eds. William Austin and Stephen Worchel (Chicago, IL: Nelson-Hall), 7-24. 
Vadher, K. and Barrett, M. 2009. Boundaries of Britishness in British Indian and Pakistani young adults. Journal of Community and Applied Social Psychology 19: 442-458.

Vignoles, V. Schwartz, S. and Luyckx, K. 2011. "Introduction: Toward an integrative view of identity," in Handbook Of Identity Theory And Research: Volume 1, eds. Seth Schwartz, Koen Luyckx and Vivian Vignoles (New York: Springer), 1-27.

Yip, A. K. T. 2004. "Embracing Allah and sexuality? South Asian non-heterosexual Muslims in Britain," in South Asians in the diaspora: Histories and religious traditions, eds. Jacobsen, K. A. and Kumar, P. P. (Leiden, the, Netherlands: Brill), 294-310 